\title{
Green Sukuk: Sustainable Financing Instruments for Infrastructure Development in Indonesia
}

\author{
Lastuti Abubakar $^{1 *}$, Tri Handayani ${ }^{1}$

\begin{abstract}
${ }^{1}$ Economic Law Department, Law Faculty, Universitas Padjadjaran, Bandung, Indonesia
${ }^{*}$ Corresponding author. Email: lastuti.abubakar@unpad.ac.id
\end{abstract}

\begin{abstract}
Sustainable development goals open opportunities for the issuance of Sukuk (Islamic securities) as an alternative to sustainable financing for infrastructure development in Indonesia. In line with the rise of public awareness of the concept of sustainable development, a new investor market has emerged. The investors will only invest in investment instruments that are categorized as "green". By applying the normative legal approach, this study analyzes green sukuk as an alternative financing for green infrastructure development in Indonesia. This study concludes that Indonesia develops Green Sukuk to support the development of green infrastructure based on the World Bank's Green Bond model. Moreover, this study proposed the green sukuk legal framework to ensure that the project meets the criteria for green infrastructure.

Keywords: Green Sukuk, green infrastructure, sustainable development goals
\end{abstract}

\section{INTRODUCTION}

The Indonesian National Medium-Term Development Plan for 2019-2024 encompasses 7 (seven) national development agendas. Two of the seven agendas are to strengthen the infrastructure to support economic development and market services as well as to build the environment, enhances disaster resilience and climate change to achieve a prosperous, just and sustainable middle-income Indonesia. [1] The challenge faced by Indonesia is on how to keep infrastructure development in harmony with environmental conservation efforts. This is one of the goals of sustainable development, i.e., Climate Action. To realize the aforementioned national development agendas, the Indonesian government has issued a green financing instrument and green infrastructure development. The target is to achieve environmentally friendly economic growth. Therefore, the Ministry of Finance issued a new investment instrument for sustainable financing, namely Green Sukuk. Green Sukuk is a good and promising way to invest in projects related to the environment. This is in line with the global trend where the world concentrates on projects based on its sustainability, especially on the environment and reforestation. Arumna Oteh, the Vice President of the World Bank Treasury at the Annual International Monetary Fund, World Bank Group, meeting in Bali in October 2018 said that if the government were fully committed to solving environmental problems, many international investors would be interested [2] Indonesia is a pioneer in issuing green bonds in the Southeast Asian region through the issuance of a Green Sukuk amounting to USD1.25 billion in March 2018. This is the first issuance of Sukuk in the world issued by a state.

The issuance of the Green Sukuk is also a manifestation of Indonesia's commitment to the Paris Agreement that was ratified on 22 April 2016. The Paris Agreement results in, among others, an agreement on a Nationally Determined Contribution (NDC) that regulates and projects the potential for reducing Greenhouse Gas (GHG) emissions of the member countries after 2020. As a follow-up, Indonesia ratified the Paris Agreement through Law No. 16 of 2016 on the Ratification of the Paris Agreement to the United Nations Framework Convention on Climate Change. At almost the same time, Indonesia submitted the NDC document to the United Nations Framework Convention on Climate Change (UNFCCC) secretariat. The NDC implementation strategy is intended as a guide to synergize all components of the community ranging from the ministries/institutions, local governments, academicians, business sectors, NonGovernmental Organizations and the general public to achieve national commitment to reduce GHG emissions and achieve low-emissions development goals and climate resilience such as contained in the NDC document. For 2020 and beyond, Indonesia aims to reach archipelagic climate resilience from comprehensive adaptation and mitigation programs, and disaster risk reduction strategies.

Climate change has a direct impact on aspects of life such as health, agriculture and the economic sectors. Climate change is believed to increase the risk of hydrometeorological disasters, which make up to $80 \%$ of disaster occurrences in Indonesia. Based on World Bank Group data in 2018, the damage of 2007 floods in Jakarta was more than USD 900 million and 7.5 million Indonesian facing acute food shortage in 1998, caused by severe droughts - attribute to El Nino, deterioration of health and poverty. Therefore, Indonesia has a strong commitment to combating climate change. This is evident from a number of actions that have been taken, namely a series of policies to reduce GHG emissions by $29 \%$ under 'Business as Usual' (BAU) and at $41 \%$ with international assistance by 2030 . To support the commitment to combatting climate change, the government needs substantial financial support for both mitigation and adaptation of climate change. It is estimated that the source of funds allocated for mitigation and adaptation actions for 2015-2019 is at USD 55.1 billion (USD 13, 78 billion/year) and will increase up to USD 81 billion (USD16.2 billion/year) in 2015-2030[3]. Hence, the results of the 
budget tagging process are used to start new financial instrument initiatives in combating climate change in the form of Green Bonds and Green Sukuk. This initiative is in line with Indonesia's goal of achieving the Sustainable Development Goals (SDG's goals), specifically the 13th goal on Climate Action.

\section{LITERATURE REVIEW}

\subsection{Definition of Indonesian Green Sukuk}

Green Sukuk are bonds that are in line with the Sharia principles as $100 \%$ of the exclusive proceeds are used to finance or refinance green projects that contribute to climate change mitigation and adaptation as well as biodiversity conservation. Thus, there are 2 criteria in the issuance of Green Sukuk: (1) the issuance of Green Sukuk must meet the Sharia and sustainable financial principles; (2) the infrastructure projects financed are projects that are in accordance with the principles of sustainable development, namely projects that integrate the environmental, social and governance (green infrastructure) aspects.

As sharia securities, Sukuk are sharia compliant securities backed by specific pools of the assets. 'Sakk' (sukuk is the plural) signifies an instrument evidencing financial obligation. A sakk represents a proportionate beneficial of ownership in an underlying pool of assets or 'usufruct'. Typically, sukuk returns are linked to returns and cash flow generated by the assets purchased or created through sukuk proceeds. Most sukuk to date have been asset- backed (e.g. infrastructure project), where credit of the originator has been decisive factor for rating and investor analysis, in accordance sharia principles. [3]

Besides fulfilling the sharia principles, the issuance of green sukuk have to comply with sustainable finance principles. In July 2017, the Indonesian Financial Services Authority (OJK) published Regulation on Sustainable Finance as a continuation of Roadmap for Sustainable Finance, which was launched in December 2014. Key opportunities of the POJK include: the POJK makes it clear that promoting balance between social, economic, and environmental factors is essential to achieving sustainable, stable and inclusive development.

In its implementation, besides the development of regulations and policies as the basis for the issuance of Green Sukuk, Indonesia has developed a Framework related to financing project through the issuance of Green Bonds and Green Sukuk. This Framework has received a second opinion from the Center for International Climate Research (CICERO) and was awarded a Medium-Green shading, allowing the possibility of types of Bright-Green, MediumGreen and Dark-Green projects. This color indicates that projects that are registered have fulfilled the requirement to represent the country's efforts towards a long-term vision in reducing carbon emissions.

\subsection{The Objective of the Issuance of Green Sukuk}

The green bond and green sukuk initiative aim to support Indonesia's goal in its GHG emissions reduction. As a part of a responsible and committed global community, Indonesia has a pivotal role in combating climate change. Its extensive tropical landscape and seascape with biodiversity high carbon stock values, energy and minerals resources are all contributing factors for the nation to be at the forefront of climate action and environmental protection.

Green sukuk is an innovative financial instrument to support Indonesia's commitment in GHG emissions reduction based on Islamic law principles. The green Sukuk issuance is guided by the Green Bond and Green Sukuk Framework, and reviewed by CICERO. With reference to the Green Bond principles, the proceeds of each Green Bond or Green Sukuk will be used exclusively to finance or re-finance expenditure directly related to Eligible Green Projects.

Eligible Green Project refer to projects which promote the transitions to low-emission economy and climate resilient growth, including mitigation, adaptation, and biodiversity in accordance with the criteria and process set out in this Framework. In accordance with the framework of Indonesian Green Bond and Green Sukuk, 9 (nine) sectors are eligible to receive Sukuk proceed as presented at the table below.

Table 1. Eligible Green Sectors

\begin{tabular}{|lll|}
\hline No & Sector & Color (shade) \\
\hline $\mathbf{1}$ & Renewable Energy & Dark green \\
\hline $\mathbf{2}$ & $\begin{array}{l}\text { Resilience to Climate for } \\
\text { Disaster Risk Area }\end{array}$ & Dark green \\
\hline $\mathbf{3}$ & $\begin{array}{l}\text { Energy \& } \\
\text { Management }\end{array}$ & $\begin{array}{l}\text { Medium to dark } \\
\text { green }\end{array}$ \\
\hline $\mathbf{4}$ & Sustainable Agriculture & Medium to dark \\
\hline $\mathbf{5}$ & Sustainable Transportation & Medium to dark \\
\hline $\mathbf{6}$ & Green Tourism Natural & Medium to dark \\
\hline $\mathbf{7}$ & $\begin{array}{l}\text { Sustainable to dark } \\
\text { Resources Management } \\
\text { green }\end{array}$ \\
\hline $\mathbf{8}$ & $\begin{array}{l}\text { Use of clean Technology for } \\
\text { Power Generation }\end{array}$ & Light to medium \\
\hline $\mathbf{9}$ & Green Building & Light green \\
\hline
\end{tabular}

Source: Indonesia's Green Sukuk, 2018

For the avoidance of doubt, in any case, the Eligible Green Projects exclude the below:

a. New fossil fuel based electric power generation capacity and expenditure related to the improvement in the efficiency of fossil fuel based electric power generation

b. Large scale hydropower plants (more than 30-Megawatt capacity)

c. Nuclear and nuclear-related assets

d. The issuance of Indonesian Green Sukuk in 2018 at USD1.25 billion is exclusively allocated for green projects that meet the requirements under the Framework, i.e., $51 \%$ for refinancing of the 2016 projects and $49 \%$ for new projects in 2018 . The sectors financed or refinanced by the 2018 Green Sukuk are Renewable Energy and Resilience to Climate Change (Dark-Green); and sustainable transportation, Waste 
Energy and Waste Management, as well as Sustainable Agriculture (Medium-Green). Several projects dedicated to climate change mitigation and adaptation activities include sustainable transportation such as the doubletrack railway project in the North Java Line and a Double Track Railway from Jakarta to Surabaya; also, renewable energy such as the Tambolaka Airport-Sumba East Nusa Tenggara Solar Power Plant Project.

\section{DISCUSSION}

\subsection{Green Sukuk As Financing and Investment Instruments}

From a legal perspective, Green Sukuk is a financing and investment instrument that must meet 2 legal principles, namely compliance with sharia principles and sustainable financial principles. Compliance with Sharia principles refers to regulations whose legal sources refer to the National Sharia Council Fatwa. According to the Fatwa, the mechanism for sukuk issuance must avoid speculation, gambling, unreasonably uncertain or ambiguous contract, taking advantage of the counterparty's ignore, corruption, and more importantly, financial returns not correlated to real activity with a certain level of risk, i.e. the concept of usury but also intended as interest. This is the most striking distinction between conventional and Islamic finance is the restriction of usury, which converts into a denial on interest [4].

Unlike the Green Bond that is a debt instrument, Green Sukuk places the holder as the owner of some undivided share of underlying assets. Thus, Sukuk holders will benefit from the management of the Sukuk underlying assets [5]. This is in line with the definition of Sukuk according to the Financial Services Authority Regulation No. 18/POJK.04/2015 that regulates that Sukuk as Sharia Securities in the form of certificates or proof of ownership of equal value and representing an undivided share of the underlying assets[6].To ensure that Green Sukuk complies with the Sharia principles, a Sharia Compliance statement issued by the National Sharia Council-Indonesian Ulema Council (DSN-MUI) is required.

The Green Sukuk issued by the state (Sovereign Sukuk) refers to the Law No. 19 of 2008 on Government Sharia Securities. Sovereign Sukuk includes state securities issued based on Sharia principles as evidence of the investment in Sharia Securities, both in Indonesian Rupiah and foreign currencies.

In addition, as part of financial instruments, Green Sukuk must apply the principles of sustainable finance set out in the 2015-2019 Sustainable Finance Roadmap in Indonesia and Regulation of the Financial Service Authority (POJK) No. 51 of 2017 on Sustainable Finance. The implementation of sustainable finance as referred to in Article 2 paragraph (2) POJK shall be performed by using principles of responsible investment; sustainable business strategy and practice; social and environmental risk management; principle of governance; informative communication principles; inclusiveness principle; principle of priority prime sector development; and principles of coordination and collaboration.

The issuance of Green Sukuk is one of the government's efforts in implementing green financing. Green finance is a broad term that can refer to financial investment flowing into sustainable development projects and initiatives, environmental products, and policies that encourage the development of more sustainable economy. Green finance includes climate finance but is not limited to it. It also refers to a wider range of other environmental objectives, for example industrial pollution control, water sanitation, or biodiversity protection. Mitigation and adaptation finance is specifically related to climate changes related activities: mitigation financial refer to investments in projects and programs that contribute to reducing or avoiding greenhouse gas emissions (GHGs) whereas adaptation financial flows refer to investments that contribute to reducing the vulnerability of goods and persons to the effect of climate change [7].

The objective is for sustainable growth that results from harmony among the economic, social and environmental interests. Green financing consists of several dimensions, namely: 1) achieving industrial, social and economic excellence in order to reduce the threat of global warming and prevent other environmental and social problems; 2) shifting the targets towards a competitive low-carbon economy; 3) strategically promoting environmentallyfriendly investment in various business/economic sectors; 4) supporting Indonesian development principles set forth in the Medium-Term Development Plan, namely 4P (progrowth, pro-jobs, pro-poor, and pro-environment) [8].

\subsection{Indonesia Global Green Sukuk}

Indonesia is being a pioneer in the issuance of Green Sukuk, there are reasons for Indonesian Green Sukuk to benefit from the opportunities in the global market. The reasons are ease of issuance because simple characteristic of sukuk to be used as underlying assets, familiarity in preparing and due diligence of project since 2014 and familiarity in the issuance process (similar to regular sukuk); Indonesian Sukuk has gained its reputation in the global market through positive press coverage; it is an innovation of financing instruments and widely promotes sustainable financing; it increase private capital to finance sustainable investment and increase opportunities for Green Bond marketing profiles for issuers; and a diversification of investors and market access. The issuance of global green sukuk is marked as the world's first sovereign green sukuk. Indonesia global green sukuk transaction was well distributed into high quality accounts, mostly top tier fund Manager and banks. Investors distributed around the globe consisting of $32 \%$ Islamic market; $25 \%$ Asia, $15 \%$ EU, $18 \%$ USA and $10 \%$ Indonesia. [2] In the global market, new investors who are willing to invest in green projects have reached $29 \%$. 


\subsection{Futures challenges and initiative strategy}

\subsubsection{Indonesia Green Sukuk Framework}

Under administration, Indonesia has set out priority actions within the national's strategic development goals, known as Nawacita (or nine agenda priorities). This includes shifting to allow carbon and climate resilient development path is an integral part of these missions, and integrated in development policies. Many of projects being undertaken by Indonesia Government to address change mitigation and adaptation will also deliver important social benefits. The implementation of this mission involves all stakeholders.

To implement its commitment to reduce greenhouse gas, Indonesia has promulgated relevant legal and policy instruments, including the Presidential Regulation No 61/2011, National Action Plan to reduce Greenhouse Gas Emissions (RAN- GRK) and the Presidential Regulation (PERPRES) No 71/2011, the Implementation of a National GHG Inventory. In 2015, Indonesia has revised its commitment through NDC to unconditional emission reduction target of $29 \%$ (from previously 26\%), and conditional reduction target up to $41 \%$ of the business as usual scenario by 2030 (from previously by 2020). The mitigations regulations are focusing on the sector of Energy, Industrial Processes and Product Use (IPPU), Agriculture, and Forestry [2].

Indonesia has adopted the National Action Plan on Climate Change Adaptation (RAN-API), which provides a national framework for adaptation initiatives that has been mainstreamed into the National Development Plan. The medium-term goal of Indonesia's climate change adaptation strategy is $\mathrm{t}$ reduce risks on all development sectors (agriculture, water, energy, security, forestry, maritime and fisheries, health, public service, infrastructure, and urban system) by 2030 through local capacity strengthening, improved knowledge, management, convergent policy on climate change adaptation and disaster risk reduction, and application of adaptive technology.

To achieve Indonesia's strong commitment on the environment and climate change, one of comprehensive and coherent development policy is improved and funding mechanism. Therefore, Indonesia has developed a Green Bond and Green Sukuk Framework under which its plans to finance or re-finance Eligible Green Projects via the issuance Green bonds and Green Sukuk.

\subsubsection{Four Pillars for Green Sukuk}

To optimize Green Sukuk as a financing instrument and attract investors to invest in Green Sukuk, the Government needs to work on strengthening four pillars to ensure that the proceeds of Green Sukuk revenue are used properly, namely (1) the use of proceeds: $100 \%$ used for refinancing and new financing of green projects; (2) project evaluation and selection through review and approval process by Ministry of Finance and National Development Planning Agency; (3) management of proceeds as issuer guarantee $100 \%$ of proceeds use to green projects. Green bond and green sukuk proceeds will be credited to a designated account of relevant ministries for funding exclusive projects as previously defined. Allocation is managed by Ministry of Finance. The line ministries utilizing the proceeds shall track, monitor and report to Ministry of Finance, on the environmental benefits of the Eligible Green projects; (4) and reporting that is expected to include measures of reduction in greenhouse gas emissions. Ministry of Finance will prepare and publish a Green Bond and Green Sukuk annual report on the list of projects, amounts of proceeds allocated to such projects and estimation of beneficial impact. [3]

In 2015, Republic of Indonesia introduced a system for tagging of ministry budgets (budget tagging process) to identify expenditures on projects that deliver climate change benefits in accordance with the republic of Indonesia's climate objectives. The Budget Tagging Process was developed with the support of the UN Development Programmed and involved a detailed, assessment of climate benefits of projects undertaken by Line Ministries. In 2018, the Budget Tagging Process is expanded to cover climate change mitigation and adaptation involving 17 Line Ministries.

\subsubsection{Indonesia Green Sukuk Challenges}

As a relatively new financing instrument, an issuance of Green Sukuk faces several challenges. First, knowledge on Green Sukuk is limited and not widely known by stakeholders of the Ministry of Finance as a Sovereign Sukuk issuer, especially the Task Force in ministries/institutions. Not all Task Force understand the Green Sukuk business process. This becomes the challenge in the projects planning process that will be used as underlying assets. The understanding of the Green Sukuk business process of all Task Force will greatly support the success of the Green Sukuk from the stage of preparation, issuance and reporting activities. To overcome this challenge, it is needed to define clear purpose of the issuance and regulate eligible green project, management of proceeds, use of proceeds and reporting.

Second, reports of the projects related to the development progress and the benefits of projects on climate change mitigation and sustainable development. Therefore, coordination between the Ministry of Finance and the Task Force needs to be more intensive, especially to agree on the indicators used in reporting and evaluating the impact of project development. The government can consider the role of independent reviewers in the process of monitoring and reporting to meet the expected criteria. Reporting can be used as a means to provide accurate information; hence right investment decisions can be taken.

\section{CONCLUSION}

Sustainable Development Goals open up the opportunities for the issuance of Green Sukuk as an alternative financing instrument for green projects to support the Indonesian government's commitment to combat climate change. In line with increasing public awareness of the concept of sustainable development, a new investor market is developing. Investors will only invest in instruments that are 
[3] M. O. Fi. R. of \& U. Indonesia, "Indonesia's green bond \& green sukuk initiative," Jakarta.

support the development of green infrastructure based on the World Bank's Green Bond model to meet the issuance with international accepted principle. There are 9 eligible green sectors that can be funded or refinanced by Green Sukuk, namely renewable energy, resilience to climate change for disaster risk areas; energy and waste management, sustainable agriculture; sustainable transportation; green tourism; sustainable natural resource management; use of clean technology for power generation; and green building. Indonesia's Green Sukuk still facing the challenges that the stakeholders do not understand the concept of Green Sukuk and the steps to ensure that the project meets the criteria for green infrastructure. Therefore, regulations are still needed to strengthen the issuance of Green Sukuk as well as the implementation of green infrastructure projects.

\section{REFERENCES}

[1] Bappenas, "Rancangan Teknokratik Rencana Pembangunan Jangka Menengah Nasional 2020-2024,” Kementeri. PPN/Bappenas, 2019.

[2] Indonesia Ministry of FInance, "The Republic Of Indonesia Green Bond And Green Sukuk Framework," 2019. [Online]. Available:

https://www.djppr.kemenkeu.go.id/uploads/files/dmoda ta/in/6Publikasi/Offering Circular/ROI Green Bond and Green Sukuk Framework.pdf.
[4] D. Morea and L. A. Poggi, "An innovative model for the sustainability of investments in the wind energy sector: The use of green sukuk in an Italian case study," Int. J. Energy Econ. Policy, vol. 7, no. 2, pp. 53-60, 2017.

[5] L. Abubakar and T. Handayani, "Legal Infrastructure Readiness in Issuance of Sukuk (Sharia Securities) as an Financing and Investment Instrument to Empower Indonesian Sharia Capital Market," J. Jurisprud., vol. 7, no. 1, p. 1, 2017.

[6] Suminto, "Green Sukuk : Financing The Future Director of Islamic Financing Indonesia 's Climate Change Vulnerability , Commitment, and," 2018, pp. $1-10$.

[7] IDFC (International Development Finance Club), “Green Finance Mapping Report 2018," 2018.

[8] OJK, Roadmap Keuangan Berkelanjutan di Indonesia Roadmap for Sustainable Finance in Indonesia. Jakarta: OJK, 2014. 